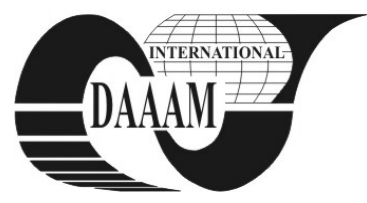

Annals of DAAAM for 2011 \& Proceedings of the 22nd International DAAAM Symposium, Volume 22, No. 1, ISSN 1726-9679 ISBN 978-3-901509-83-4, Editor B. Katalinic, Published by DAAAM International, Vienna, Austria, EU, 2011 Make Harmony between Technology and Nature, and Your Mind will Fly Free as a Bird Annals \& Proceedings of DAAAM International 2011

\title{
INTELLIGENT POSITIONING SYSTEM OF ELECTRO-PNEUMATIC SERVO-DRIVE
}

\author{
TAKOSOGLU, J[akub] E[manuel] \& LASKI, P[awel] A[ndrzej]
}

\begin{abstract}
In paper a Fuzzy Logic Controller of PD type to positioning control and teaching/play-back control of electropneumatic servo-drive are presented. The analysed fuzzy logic controller carry out a tasks: transpose control, follow-up control and teaching/play-back control. The fuzzy logic PD controller enables precise positioning of pneumatic servo-drive with the precision specified for industrial manipulators. A lot of simulation and experimental tests were carried on pneumatic servo-drive with fuzzy controller which was used for its transponse and follow-up control. The designed fuzzy system is efficient, stable and resistant to disturbances and can be applied in any configurations of pneumatic servo-drive without necessity to tune the regulator, apply signal filtration or additional operations in track control or restrict the signals generated. The teaching/play-back control system using fuzzy logic control was constructed and practically applied in various servo-pneumatic systems used in production automation. By comparison with a industrial controller, FLC haven't a restrict the time and number of measurement data and a control is in real time.
\end{abstract}

Key words: fuzzy control, electro-pneumatic servo-drive, pneumatic cylinder, pneumatic servo-valve, positioning system

\section{INTRODUCTION}

The development of automation and robotics increases interest in pneumatic servo-drive, which are highly dynamic, reliable and low manufacturing costs. However, due to unsatisfactory positioning accuracy of pneumatic servo-drive their application in industrial manipulators is restricted. The problem of positioning accuracy of servo-pneumatic systems is difficult to solve when no sufficient information on the process of conversion of the compressed gas energy into mechanical energy of pneumatic cylinder is available. Therefore new control methods based on artificial intelligence, for example, fuzzy logic are introduced. Fuzzy control system improved dynamics and positioning accuracy of electro-pneumatic servodrive and eliminated disturbances in its control system. Pneumatic servo-drive with teaching/play-back fuzzy control system the physiotherapy and rehability manipulator is being constructed.

\section{RESEARCH STAND}

The view of research stand used to conduct experiments on fuzzy logic control of electro-pneumatic servo-drive are presented in Fig. 1. Diagram of control system are presented in Fig. 2.

The test stand consists of the following elements:

- pneumatic rodless cylinder DGPL-25-224 (Festo) with piston diameter of $25 \mathrm{~mm}$ and stroke length of $224 \mathrm{~mm}$,

- proportional 5/3 directional control valve MPYE-5-1/8-HF010-B (Festo) controlled by $0-10 \mathrm{~V}$ voltage of nominal flow rate $700 \mathrm{l} / \mathrm{min}$ and switching frequency $75 \mathrm{~Hz}$,
- non-contact micropulse displacement transducer BTL5A11-M0600-P-S32 (Balluff), analog output signal - voltage $0-10 \mathrm{~V}$,

- 16-bit measurement card AD/DA PCI-DAS1602/16 (Measurement Computing Corporation) with 8 analog inputs and 2 outputs,

- PC computers Host and Target.

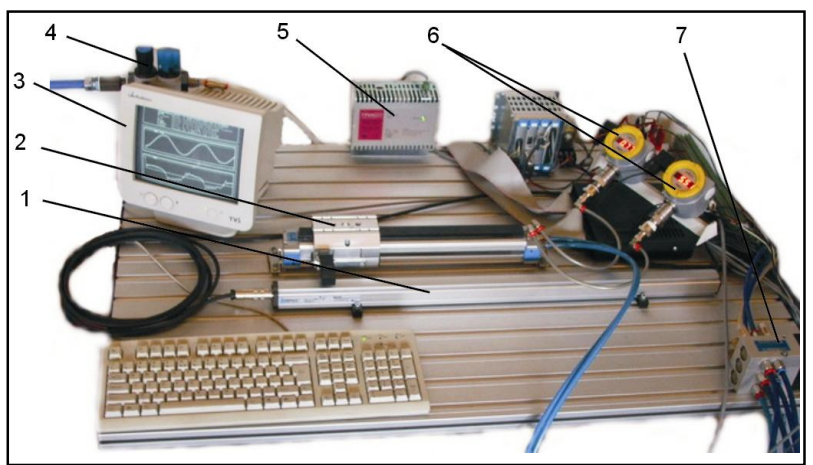

Fig. 1. General view of the research stand of electro-pneumatic servo-drive single axis positioning system: 1 - position transducer, 2 - rodless cylinder, 3 - xPC Target computer screen, 4 - pneumatic F.R. unit, 5 - power supply, 6 - pressure transducer, 7 - servo-valve

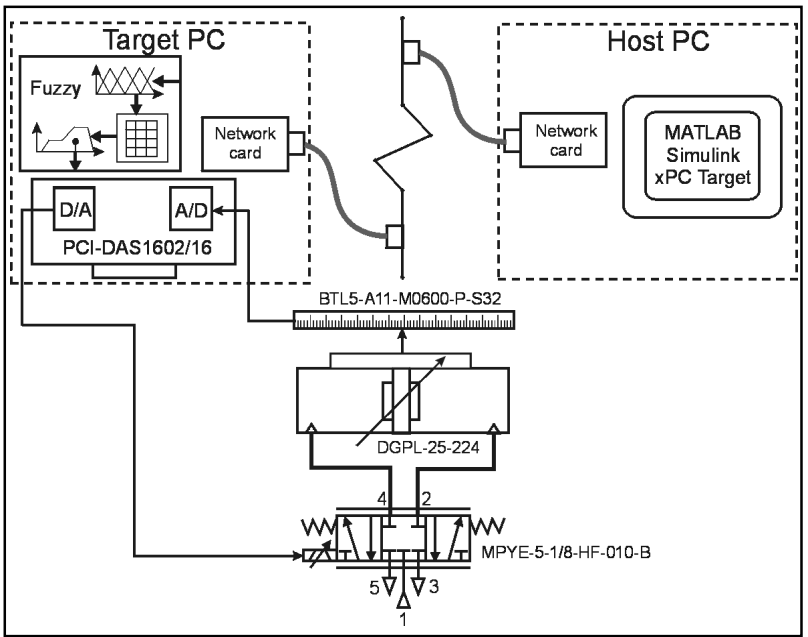

Fig. 2. The diagram of pneumatic servo-drive control system

System with teaching/play-back control of additional potentiometer position transducer was expanded which is motion trajectory adjuster.

In the computer marked as Host in Fig. 2 the software Matlab-Simulink together with xPC Target for rapid prototyping and simulation in the loop in real time control were installed. Target possesses an analog I/O card and a Real-Time xPC Target system which activates measurement data and controls pneumatic servo-drive. Host and Target communicate 
with each other by means of the TCP/IP protocol. Our work with the package for rapid prototyping consisted in construction and compilation of Simulink model, and sending the compiled model onto Target which together with analog I/O card and Real-Time xPC Target system functioned as real controller. Thanks to xPC Target software, the measurement, diagnosic and visualization of the analyzed control process was possible.

\section{FUZZY LOGIC CONTROLER}

To positioning control of pneumatic servo-drive a fuzzy logic controller (FLC) of PD type with two inputs $e(t)$ (position error), $\Delta e(t)$ (change of position error) and one output $u(t)$ (voltage in the coil servovalve) (Fig. 3) was used (Takosoglu et al., 2009). The fuzzy controller operates on knowledge base containing IF-THEN rules (Driankov et al., 1996) for undetermined predicates and fuzzy control mechanism (Yager et al., 1994):

$$
\begin{aligned}
u(k)= & F[e(k), e(k-1), \ldots, e(k-v), u(k-1), u(k- \\
& 2) u(k-v)]
\end{aligned}
$$

where:

$u(k)$ - control signal describing relation between controller's input and output,

$e(k)$-position error between input signal $y_{0}(k)$ and output signal $y(k)$,

$k$-discrete time (sampling instant), $k=t / T$,

$t$-continuous time,

$T$-sampling period.

$v$ - parameter determining controller's order,

$F$ - nonlinear function describing database rules of FLC (Yager et al., 1994).

FLC's input and output signals were subjected to fuzzyfication process with triangular and trapezoid membership function of fuzzy sets distribution type. In the fuzzyfication process the firing degree of MIN type, fuzzy implication of MIN type and aggregation of particular outputs of the rule of MAX type were determined. In order to obtain crisp value the method of the Centre of Gravity (Takosoglu et al., 2010) was used. Twenty five FLC's database rules (Tab. 1) forming FLC's control surface (Fig. 3).

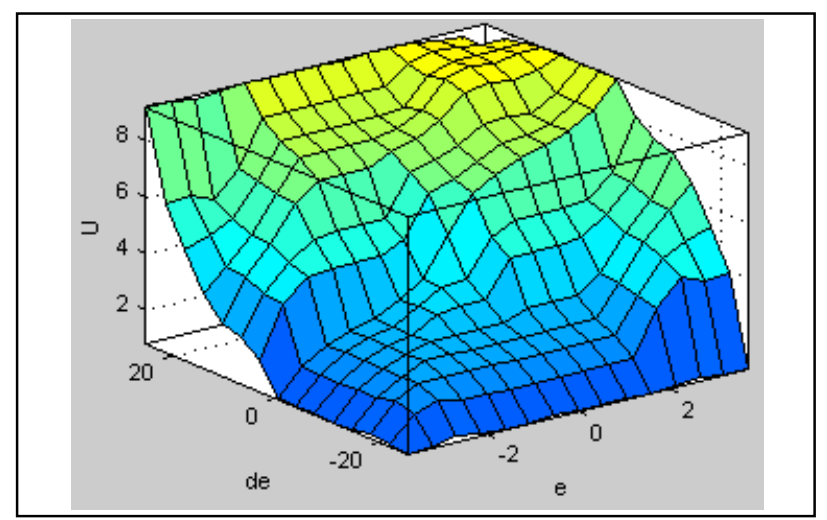

Fig. 3. Control surface

\begin{tabular}{|c|c|c|c|c|c|c|c|}
\hline$\Delta$ ele & NB & NM & NS & Z & PS & PM & PB \\
\hline NB & NB & NB & NB & NB & NM & NS & Z \\
\hline NM & NB & NB & NM & NM & NS & Z & PS \\
\hline NS & NB & NM & NS & NS & Z & PS & PM \\
\hline Z & NB & NM & NS & Z & PS & PM & PB \\
\hline PS & NM & NS & Z & PS & PS & PM & PB \\
\hline PM & NS & Z & PS & PM & PM & PB & PB \\
\hline PB & Z & PS & PM & PB & PB & PB & PB \\
\hline
\end{tabular}

Tab. 1. Database rules

\section{RESULTS OF EXPERIMENTAL TESTS}

Transpose, follow-up and teaching/play-back control of pneumatic servo-drive motion were carried out. Some graph of positioning electro-pneumatic servo-drive are presented in Fig. 4. The performance control of fuzzy controller was checked by means of standard and additional performance index (Dzierzek et al., 2010; Wang et al., 2009).

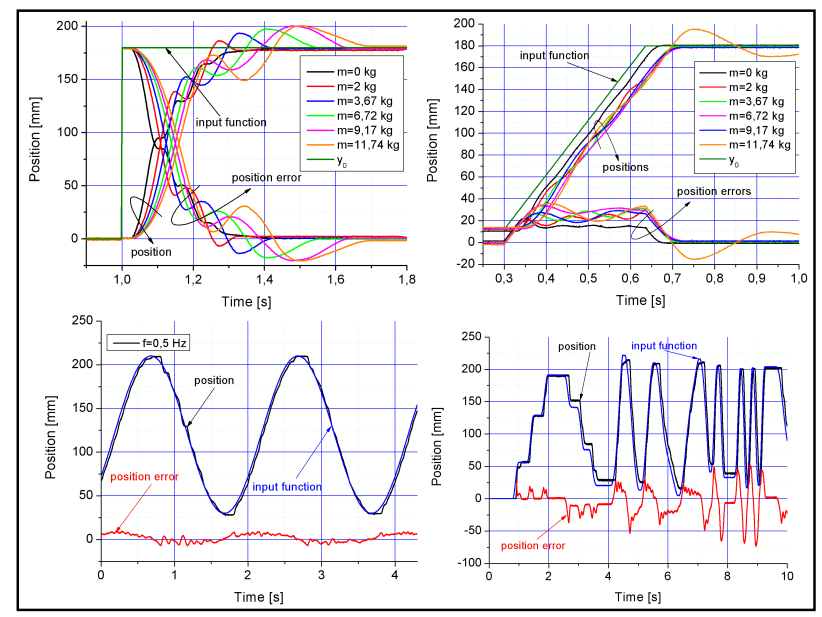

Fig. 4. Experimental results positioning control of electropneumatic servo-drive

\section{CONCLUSION}

The analysed fuzzy logic controller carry out a tasks: transpose control, follow-up control and teaching/play-back control. The fuzzy logic PD controller enables precise positioning of pneumatic servo-drive with the precision specified for industrial manipulators. The designed fuzzy system is efficient, stable and resistant to disturbances and can be applied in any configurations of pneumatic servo-drive without necessity to tune the regulator, apply signal filtration or additional operations in track control or restrict the signals generated. The teaching/play-back control system using fuzzy logic control was constructed and practically applied in various servo-pneumatic systems used in production automation. The designed fuzzy system processes a measurement data every $0,5 \mathrm{~ms}$.

\section{REFERENCES}

Driankov, D.; Hellendoorn, H.; Reinfrank, M. (1996). An introduction to fuzzy control, WNT, ISBN: 83-204-2030-X, Warsaw

Dzierzek, K.; Siemieniako, F. (2010) Analysis of quality of relay control systems with correction. Acta Mechanica Slovaca. Vol. 14, No. 2, 86-90, ISSN: 1335-2393

Takosoglu, J. E.; Dindorf, R. F.; Laski, P. A. (2009). Rapid prototyping of fuzzy controller pneumatic servo-system. International Journal of Advanced Manufacturing Technology, Vol. 40, No. 3-4, 01.2009 349-361, ISSN: 0268-3768

Takosoglu, J. E.; Dindorf, R. F.; Laski, P. A. (2010). Fuzzy logic positioning system of electro-pneumatic servo-drive, In: Robot Manipulators, Trends and Development, Jimenez A., Al Hadithi B. M., 298-320, In-Tech, ISBN 978-953307-073-5, Croatia

Wang, Y-T.; Wong R-H., Lo J-H. (2009). CCD-based twodimensional pneumatic arm control system. Journal of Systems and Control Engineering, Vol. 223, No. I5, 08.2009 585-590, ISSN 0959-6518

Yager, R. R.; Filev, D. P. (1994) Essentials of fuzzy modeling and control, WNT, ISBN: 83-204-1909-3,Warsaw 